\title{
Highly Elastic Fibers Made from Hydrogen-Bonded Polymer Complex
}

\author{
Jiefu Li ${ }^{a, b}$, Zhiliang Wang ${ }^{a, b}$, Lingang Wen ${ }^{a, b}$, Jing Nie ${ }^{a, b}$, \\ Shuguang Yang* ${ }^{a, b}$, Jian $\mathrm{Xu}^{\mathrm{c}}$, Stephen Z. D. Cheng ${ }^{b, d}$
}

${ }^{a}$ State Key Laboratory for Modification of Chemical Fibers and Polymer Materials \& College of Material Science and Engineering, Donghua University, Shanghai 201620

${ }^{b}$ Center for Advanced Low-dimension Materials, Donghua University, Shanghai 201620

${ }^{c}$ Laboratory of Polymer Physics and Chemistry, Institute of Chemistry, Chinese Academy of Sciences, Beijing 100190

${ }^{d}$ Department of Polymer Science, The University of Akron, Ohio 44325, USA

*To whom correspondence should be addressed: shgyang@dhu.edu.cn

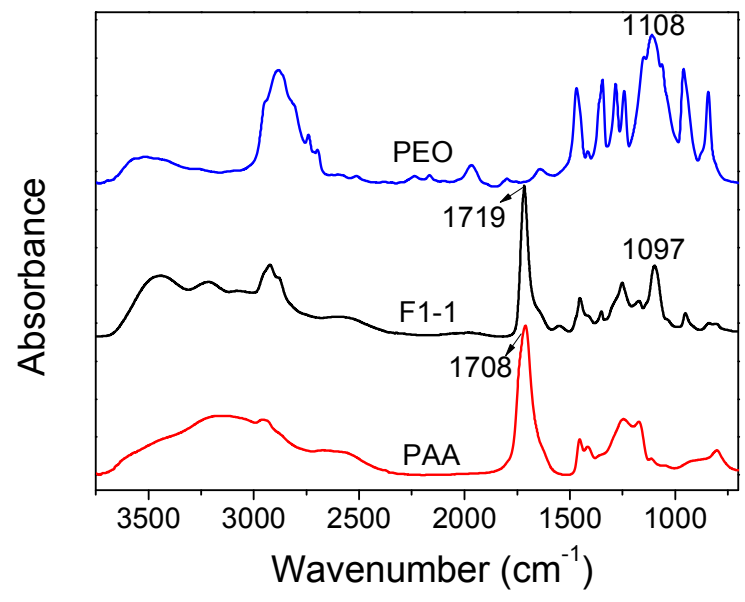

Figure S1 FTIR spectra of PEO, PAA and fiber F1-1 


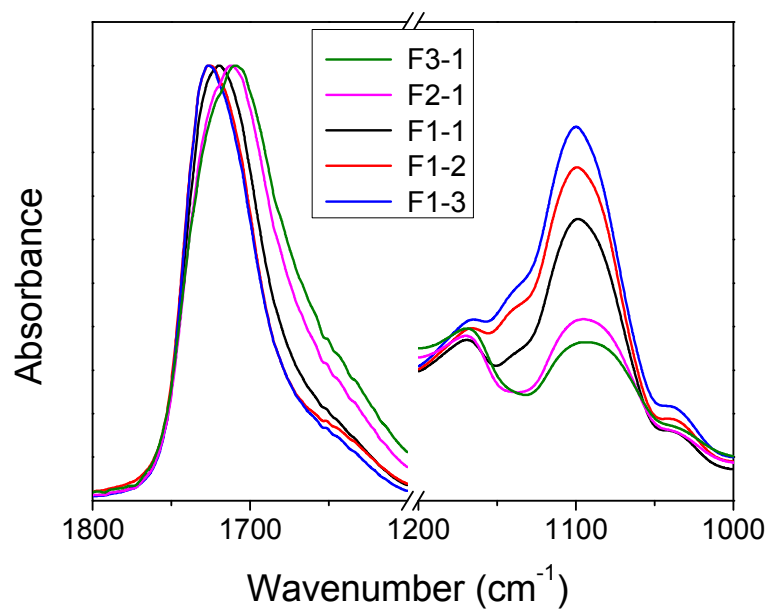

Figure S2 FTIR spectra of fiber F3-1, F2-1, F1-1, F1-2 and F1-3.

The $\mathrm{C}=\mathrm{O}$ stretching vibration peaks of PAA in fiber F3-1, F2-1, F1-1, F1-2, and F1-3 are located at 1710,1712, 1719, 1726, and $1727 \mathrm{~cm}^{-1}$, respectively. As the PEO content in the PAA/PEO fiber increases, the $\mathrm{C}=\mathrm{O}$ stretching vibration of PAA moves to higher frequency. The $\mathrm{C}=\mathrm{O}$ stretching of free $\mathrm{COOH}$ is located around $1745 \mathrm{~cm}^{-1}$. ${ }^{[1]}$ However in PAA, there are several different hydrogen bonding modes among $\mathrm{COOH}$ groups, which result in a $\mathrm{C}=\mathrm{O}$ stretching vibration located at $1709 \mathrm{~cm}^{-1} .{ }^{[2,3]}$ In the PAA/PEO fiber, besides hydrogen bonds between carboxylic groups of PAA and oxygens of PEO, hydrogen bonds link only carboxylic groups. As the PEO content in fiber increases, almost all $\mathrm{COOH}$ groups form hydrogen bonds with ether oxygens, so the $\mathrm{C}=\mathrm{O}$ stretching vibration peak moves to higher frequencies. The peaks of $\mathrm{C}-\mathrm{O}-\mathrm{C}$, the stretching vibrations can also reflect the hydrogen bonding state of PAA/PEO. For amorphous non-bonded C-O-C stretching vibration of PEO is at $1107 \mathrm{~cm}^{-1} .{ }^{[1]}$ When PEO forms hydrogen bonds with PAA, the C-O-C stretching vibration peak shows a red shift. As PEO content in the fiber increases, the red shift becomes smaller. 


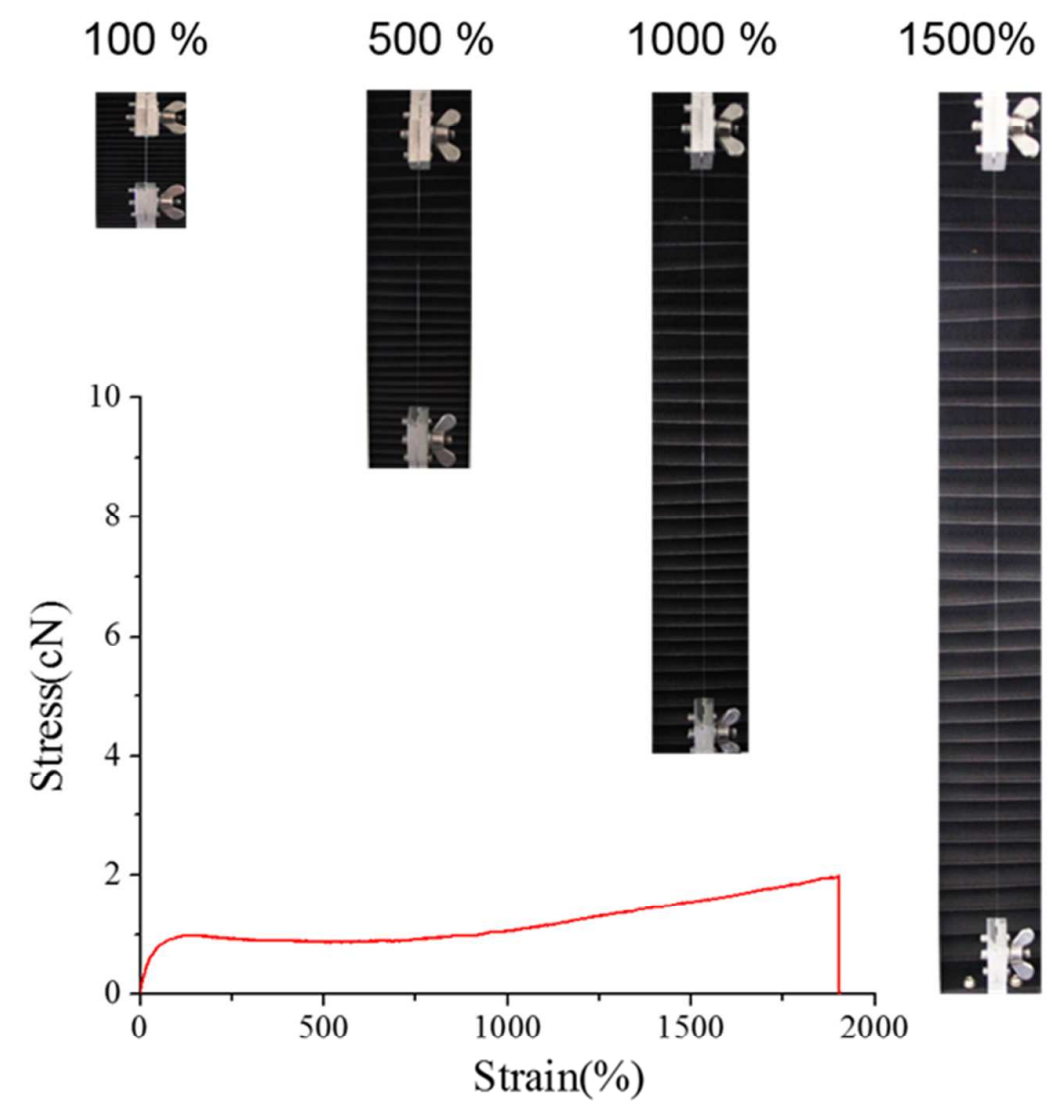

Figure S3 tensile curve and pictures of a PEO/PAA fiber. 


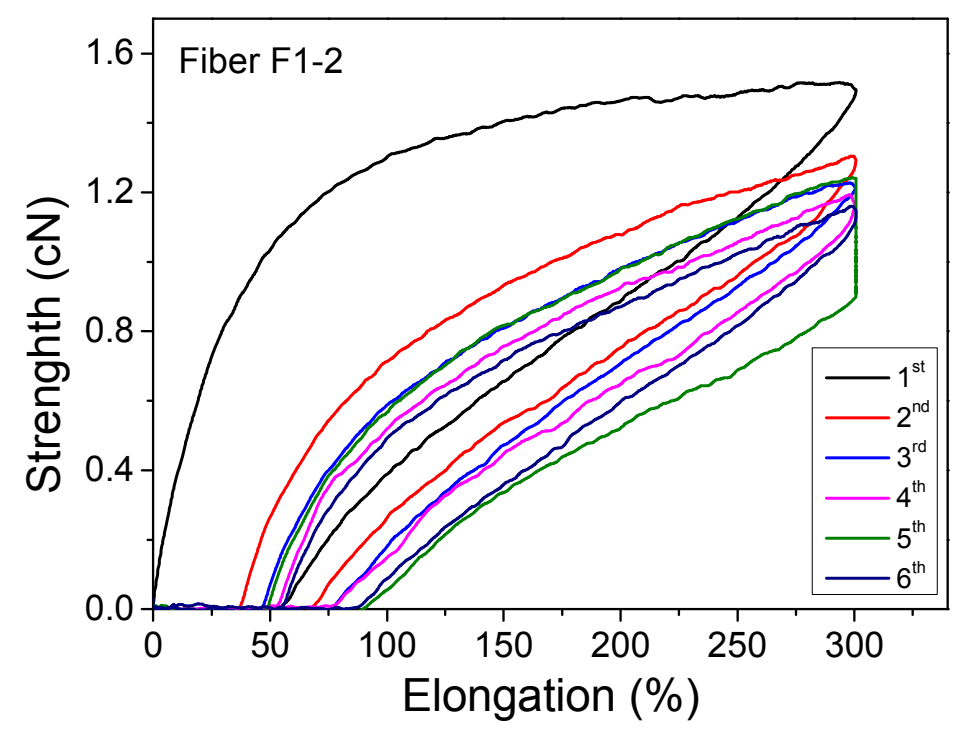

Figure S4 Record curves of the elastic recovery tests.

Elastic recovery tests were measured using an electronic single fiber strength tester. The test method was referenced the standard of Chinese Textile Industry (FZ/T 5007-2012). Twenty-millimeter long fibers $\left(\mathrm{L}_{0}\right)$ are extended to $300 \%$ elongation $\left(\mathrm{L}_{1}\right)$ at a strain rate of $100 \mathrm{~mm} / \mathrm{min}$ and allowed to relax. The extension-relaxation process was repeated 4 times. In the fifth cycle, the crosshead is stopped at the maximum extension for $30 \mathrm{~s}$, and then relaxed. In the sixth cycle, when the stress appeared, the fiber length is defined as $\mathrm{L}_{2}$. The elastic recovery rates are calculated as below:

$$
E_{R i}=\frac{L_{1}-L_{2}}{L_{1}-L_{0}} * 100 \%
$$

where $E_{R i}$ is the elastic recovery rate, $L_{0}$ is clamping length, $L_{1}$ is the length when extended to $300 \%$ elongation, and $\mathrm{L}_{2}$ is the fiber length in the sixth cycle when the stress on fiber appear. 


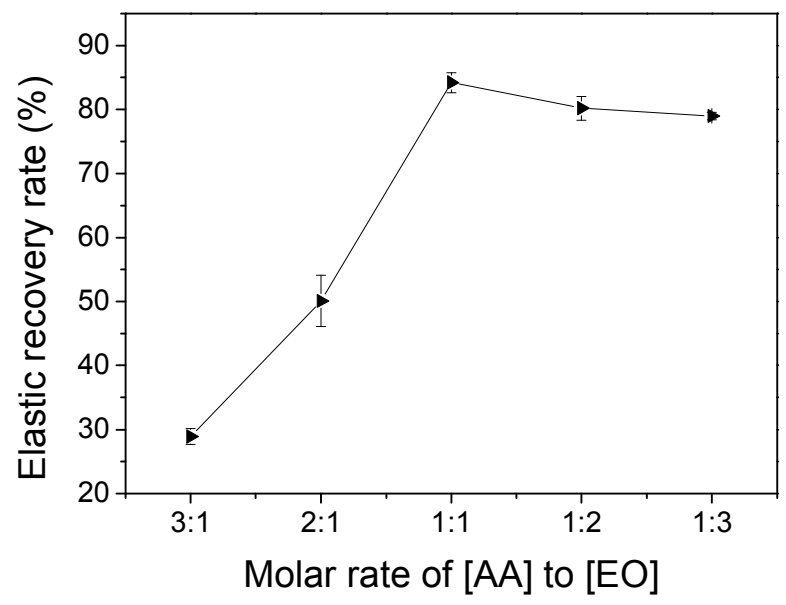

Figure S5 Elastic recovery rates after six stretching cycles of the fibers to $300 \%$ elongation at a speed of $100 \mathrm{~mm} / \mathrm{min}$.

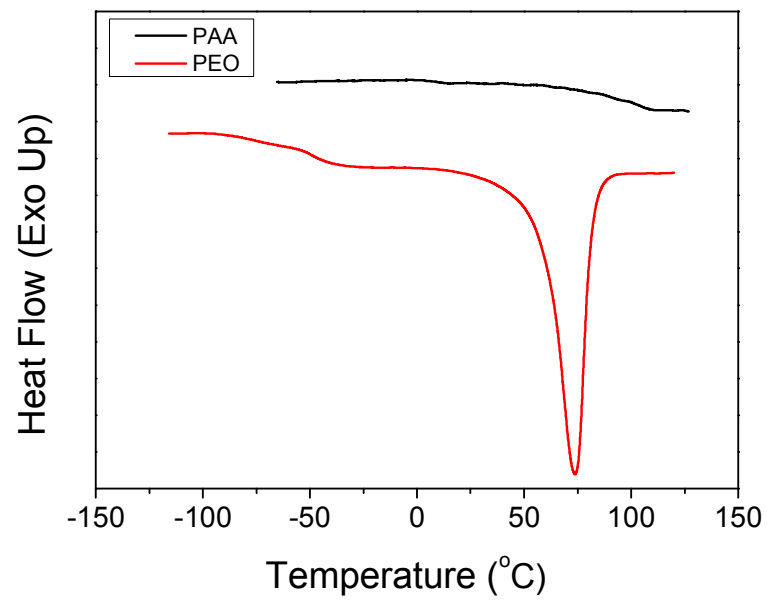

Figure S6 DSC curves of PAA and PEO 


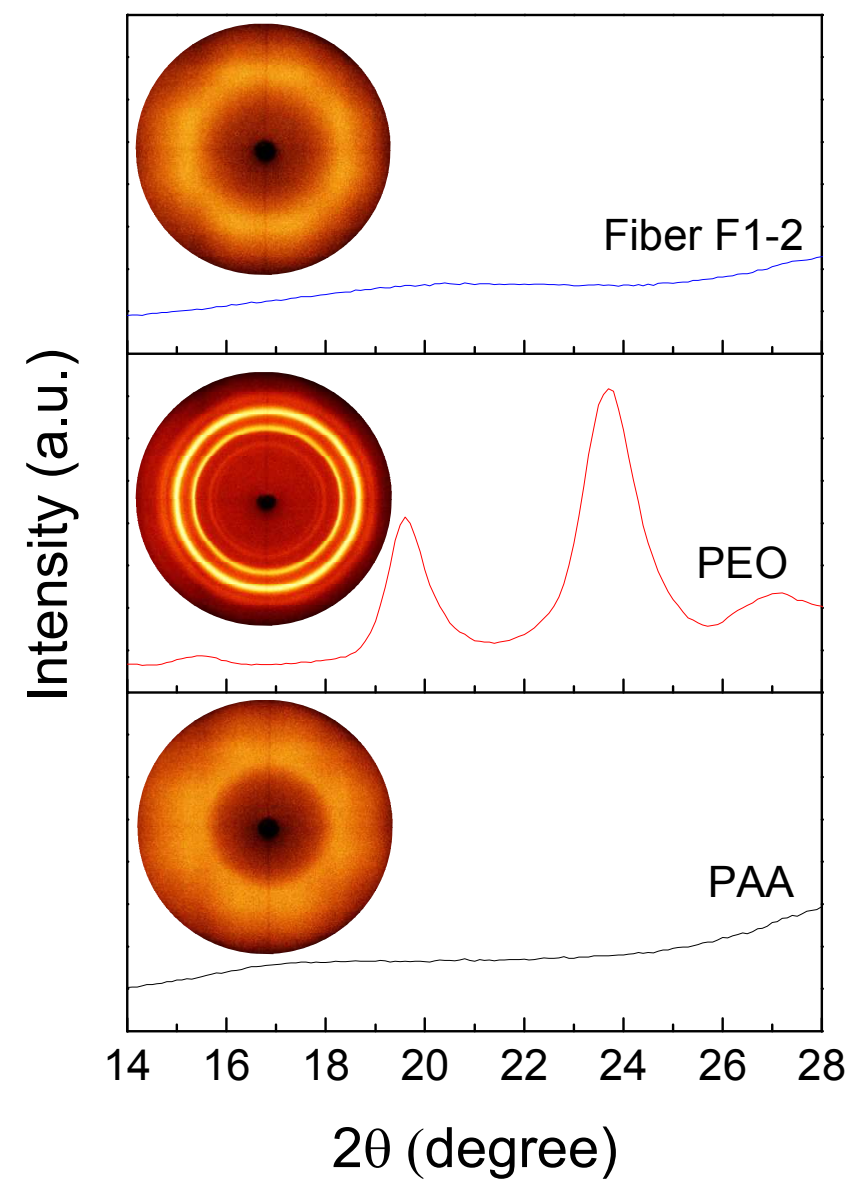

Figure S7 XRD pattern of PAA/PEO fiber, PEO and PAA

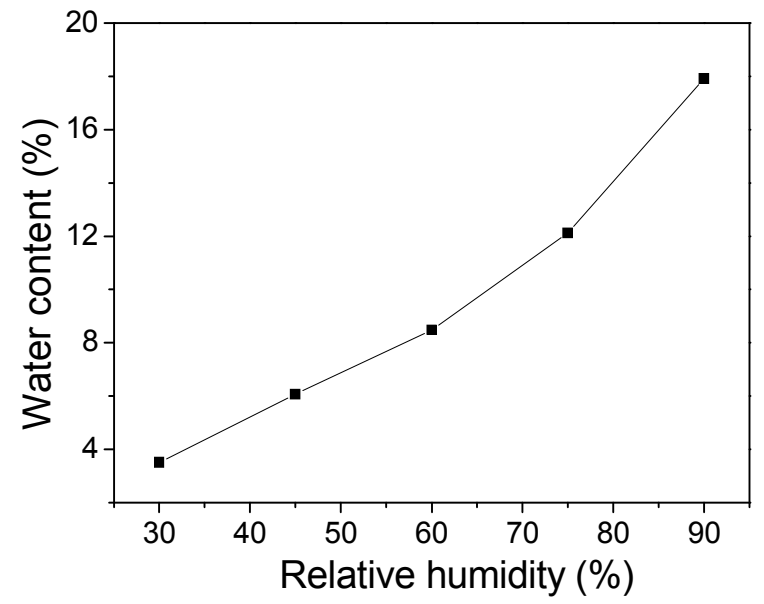


Figure S8 Water contents of fiber F1-2 after treatment at different relative humidity

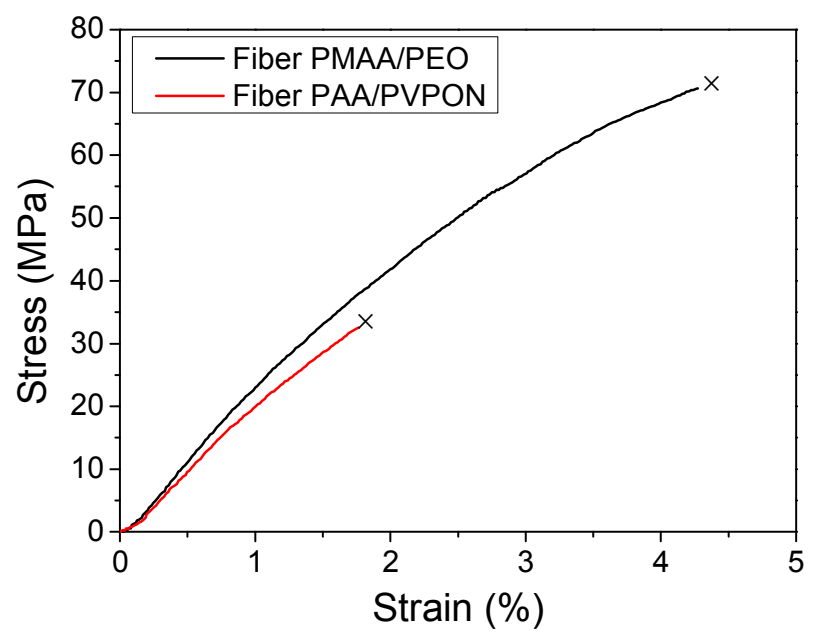

Figure S9 Stress-strain curves of fiber PMAA/PEO and fiber PAA/PVPON obtained by stretching a $20 \mathrm{~mm}$ long fiber at a strain rate of $40 \mathrm{~mm} / \mathrm{min}$ at $20{ }^{\circ} \mathrm{C}$ and $\mathrm{RH} 65 \%$.

\section{References}

[1] J. B. Thomas, J. H. Tingsanchali, A. M. Rosales, C. M. Creecy, J. W. McGinity, N. A. Peppas, Polymer 2007, 48, 5042-5048.

[2] J. Dong, Y. Ozaki, K. Nakashima, Macromolecules 1997, 30, 1111-1117

[3] J. A. Venegas-Sanchez, M. Tagaya, T. Kobayashi, Polym. J 2013, 45, 1224-1233. 